\title{
PERILAKU IBU DALAM MEMILIH TENAGA PENOLONG PERSALINAN DI WILAYAH KERJA PUSKESMAS TEMBILAHAN HULU TAHUN 2016
}

\author{
Alhidayati $^{1}$, Asmuliyanti ${ }^{2}$
}

\begin{abstract}
Background: Maternal Mortality Rate (MMR) is an indicator of health development in Indonesia. Some effort have been done to decrease maternal mortality ie to increase range labor by health personnel. The target coverage of labor by health personnel in Tembilahan Hulu Public health center has yet to reach the target of $80 \%$. its coverage was only $45 \%$. The number of maternal mortality in Tembilahan Hulu Health center in 2016 was 1 cases and the number of infant maternal mortality was 5 cases.

Objective: The purpose of this study was to determine the mother's behavior in selecting birth attendants in health center in the region of the upstream Tembilahan Hulu.

Method: This research used qualitative method to gain the in depth information on how to Mother's Behavior In Selecting Birth Attendants In Health Centers Working Area Tembilahan Hulu 2016. The data are analysed by using content analysis, which is comparing the result from the research with the theories in the literature.
\end{abstract}

Result and Discussion: There were 13 informants in this research. This study's result showed that the decision for birth attendants were closely related to knowledge, attitude, socio-cultural, access to health center, and support from family.

Advise to relevant agencies, namely health centers Tembilahan Hulu order to further increase coverage deliveries by health care and in personels villages to which access is far from health facilities to build Birth Waiting Homes (BWH).

Conclusion: The Decision for birth attendants were closely related to knowledge, attitude, socio cultural, acces to health center and support from family.

Keywords: birth attendant, community health center, pregnant women behavior

\begin{abstract}
ABSTRAK
Latar Belakang: Angka Kematian Ibu (AKI) merupakan salah satu indikator pembangunan kesehatan di Indonesia. Pertolongan persalinan oleh tenaga kesehatan menjadi sangat penting dalam upaya penurunan angka kematian ibu. Cakupan persalinan yang ditolong oleh tenaga kesehatan di Puskesmas Tembilahan Hulu masih belum mencapai target $90 \%$. Target Puskesmas Tembilahan Hulu yaitu $80 \%$ tetapi yang tercapai hanya 45\%. Jumlah Kematian Ibu di Puskesmas Tembilahan Hulu tahun 2016 sebanyak 1 kasus dan Jumlah Kematian Bayi sebanyak 5 Kasus, salah satu penyebab kematian ditangani oleh dukun bayi.

Tujuan: Tujuan dari penelitian ini adalah untuk mengetahui perilaku ibu dalam memilih tenaga penolong persalinan di wilayah kerja puskesmas Tembilahan Hulu.

Metode: Jenis penelitian yang digunakan adalah penelitian kualitatif, untuk mendapatkan informasi yang lebih mendalam tentang bagaimana Perilaku Ibu dalam Memilih Tenaga Penolong Persalinan di Wilayah Kerja Puskesmas Tembilahan Hulu Tahun 2016. Data dianalisis dengan menggunakan analisis isi yaitu membandingkan hasil penelitian dengan teori-teori yang ada di kepustakaan.
\end{abstract}

\footnotetext{
1,2 Program Studi Ilmu Kesehatan Masyarakat STIKes Hang Tuah Pekanbaru
} 
Hasil dan Pembahasan: Informan dalam penelitian ini sebanyak 13 informan. Hasil penelitian menunjukkan keputusan ibu memilih penolong persalinan sangat berkaitan dengan pengetahuan, sikap, sosial budaya, akses ke pelayanan kesehatan, dukungan keluarga.

Disarankan ke instansi terkait yaitu Puskesmas Tembilahan Hulu agar lebih meningkatkan cakupan pertolongan persalinan di tenaga kesehatan dan di setiap desa yang aksesnya jauh dari fasilitas kesehatan agar dibuat Rumah Tunggu Kelahiran (RTK).

Kesimpulan: Perilaku ibu memilih tenaga kesehatan berkaitan dengan pengetahuan, sikap, dan aspek sosial budaya, akses ke fasilitas kesehatan dan dukungan keluarga.

Kata kunci: tenaga penolong persalinan, puskesmas, perilaku ibu hamil

\section{PENDAHULUAN}

Pemilihan penolong persalinan merupakan salah satu upaya yang dilakukan untuk mencari pertolongan dalam menghadapi proses persalinan. Pemilihan tenaga penolong persalinan merupakan salah satu hak reproduksi perorangan dalam menentukan dimana akan melahirkan serta siapa yang akan menolong persalinan. Persalinan yang aman memastikan bahwa semua penolong persalinan mempunyai pengetahuan, keterampilan dan alat untuk memberikan pertolongan yang aman dan bersih, serta memberikan pelayanan nifas kepada ibu dan bayi. ${ }^{1}$

Pemilihan tenaga penolong persalinan pada tenaga non kesehatan (dukun bayi) seringkali menimbulkan dampak yang akan menyebabkan angka kesakitan ibu dan bayi, juga komplikasi persalinan, bahkan kematian pada ibu bersalin dan bayinya. Dapat dipahami bahwa dukun bayi tidak dapat mengetahui tanda-tanda bahaya persalinan, akibatnya terjadi pertolongan persalinan yang tidak adekuat. Hal ini merupakan salah satu penyebab tidak langsung kematian ibu dan bayi baru lahir. ${ }^{1}$

Penyebab langsung kematian ibu, antara lain perdarahan, infeksi, eklampsia, persalinan lama dan keguguran. Namun, faktor lain yang menyebabkan kematian ibu adalah kuantitas dan kualitas tenaga penolong. Masih ada pertolongan persalinan yang dilakukan oleh dukun bayi dengan menggunakan cara-cara tradisional. Kurangnya pengetahuan dan perilaku masyarakat dalam mencari informasi tentang kesehatan ibu, keterbatasan perempuan mengambil keputusan untuk kepentingan kesehatan dirinya ditengarai menyebabkan keterlambatan tersebut. Oleh karena itu semua ibu hamil agar dilanjutkan bersalin ke tenaga kesehatan agar jika terjadi

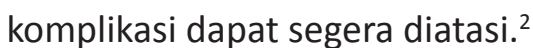

WHO meluncurkan strategi Making Pregnancy Safer (MPS). MPS membantu untuk meningkatkan kesehatan ibu, membantu negara-negara untuk menjamin tenaga kesehatan terampil sebelum, selama dan setelah kehamilan. Setiap menit, setidaknya satu perempuan meninggal akibat komplikasi yang berhubungan dengan kehamilan atau persalinan yang berarti 529.000 orang ibu pertahun (WHO, 2009). Penyebab utama kematian ibu, tidak tersedianya sarana kesehatan, jauh dari sarana kesehatan, tidak terjangkau fasilitas kesehatan, atau buruknya kualitas perawatan dari petugas kesehatan (Depkes RI, 2014). Cakupaan pertolongan persalinan oleh tenaga kesehatan secara Nasional adalah sebesar 90,88\%. Hasil Survey Demografi dan Kesehatan (SDKI) 2012, Angka Kematian Ibu (AKI) di Indonesia masih tinggi yaitu 359/100.000 kelahiran hidup dan 
Angka Kematian Bayi (AKB) 32/1000 kelahiran hidup. Di Indonesia Persalinan yang ditolong oleh tenaga non kesehatan adalah $25-35 \%^{3}$, sementara target cakupan persalinan oleh tenaga kesehatan tahun 2015 adalah $90 \%{ }^{4}$

Provinsi Riau cakupan persalinan oleh tenaga kesehatan adalah $79,86 \%$ dan ditolong oleh non kesehatan adalah $20,14 \%$. Penyebab kematian ibu yaitu perdarahan $42,7 \%$, lainnya 30\%, hipertensi 27,3\% (Profil Kesehatan Provinsi Riau, 2015). Masyarakat Indonesia lekat dengan segala macam tradisi, termasuk dalam hal melahirkan. Peran dukun bayi di Daerah terpencil bahkan nyaris tak tergantikan. Dukun bayi selalu ada dalam setiap peristiwa kelahiran, terutama pada masyarakat pedesaan. Padahal bukan rahasia lagi jika dukun bayi sebetulnya memiliki kompetensi yang minim. Kompetensi yang minim meningkatkan resiko ibu mengalami perdarahan bahkan kematian. Namun kenyataan ini tak menyurutkan niat ibu melahirkan menggunakan jasa dukun bayi.

Berdasarkan survey awal di Puskesmas Tembilah Hulu, ditemukan beberapa ibu bersalin yang berada di Wilayah Kerja Puskesmas Tembilahan Hulu, melakukan persalinan pada dukun bayi. Mertua/orang tua yang memutuskan untuk melakukan persalinan dengan dukun bayi dengan pertimbangan lebih berpengalaman, budaya turun temurun dari orang tua, dan mudah dipanggil ke rumah serta biayanya yang murah. Penelitian ini bertujuan untuk mengetahui perilaku ibu dalam memilih tenaga penolong persalinan di wilayah kerja puskesmas Tembilahan Hulu.

\section{METODE}

Penelitian ini menggunakan metode deskriptif kualitatif, yaitu suatu pendekatan penelitian yang mengungkap situasi sosial tertentu dengan mendeskripsikan kenyataan secara benar, dibentuk oleh kata-kata berdasarkan teknik pengumpulan dan analisis data yang relevan yang diperoleh dari situasi yang alamiah.

Rancangan penelitian yang digunakan adalah fenomenologi. Penelitian fenomenologi berorientasi untuk memahami, menggali, dan menafsirkan arti dari speristiwa-peristiwa, fenomena-fenomena dan hubungan dengan orang-orang yang biasa dalam situasi tertentu. Ini biasa disebut dengan penelitian kualitatif dengan menggunakan pengamatan terhadap fenomenafenomena atau gejala-gejala sosial yang alamiah (nature). Penelitian ini dilaksanakan di Wilayah Kerja Puskesmas Tembilahan Hulu yang dilakukan pada bulan April sampai Juni 2016. Pengambilan data dilaksanakan selama 3 bulan dari bulan April sampai dengan Juni 2016. Subjek dalam penelitian ini terdiri dari beberapa kriteria sebagai berikut: Informan utama penelitian yaitu Ibu nifas 0-40 hari masa nifas, sedangkan yang menjadi informan pendukung dalam penelitian ini adalah suami informan utama, bidan, pemegang program PWS-KIA, kepala puskesmas.

\section{HASIL DAN PEMBAHASAN}

Pada penelitian ini peneliti melakukan wawancara mendalam kepada informan utama dan informan pendukung. Informan utama berjumlah 5 orang yang terdiri dari ibu nifas 0-40 hari. Informan pendukung berjumlah 8 orang yang terdiri dari suami ibu nifas, bidan, pemegang program PWS-KIA puskesmas, dan Kepala Puskesmas.

\section{a. Perilaku Ibu dalam Memilih Tenaga Penolong Persalinan}

Dari hasil wawancara mendalam informan utama tentang mengapa ibu memilih tenaga penolong persalinannya ke bidan atau ke dukun bayi karena akses yang sulit dan sudah turun temurun. 
Dari hasil penelitian yang dilakukan kepada 5 ibu nifas terhadap perilaku ibu dalam memilih tenaga penolong persalinan diketahui bahwa 3 informan utama masih memilih tenaga penolong persalinan ke dukun bayi, sementara 2 informan utama memilih tenaga pertolongan persalinan ke tenaga kesehatan (bidan).

Pada penelitian ini peneliti mendapatkan, bahwa perilaku ibu dalam memilih tenaga penolong persalinan masih banyak memilih ke tenaga non kesehatan (dukun bayi) dibandingkan ke tenaga kesehatan (bidan) dikarenakan ada beberapa alasan antara lain : karena sudah terbiasa dengan dukun bayi, akses yang sulit dan kurangnya dukungan suami untuk bersalin ke tenaga kesehatan (bidan).

\section{b. Pengetahuan}

Dari hasil wawancara mendalam informan utama tentang pengertian persalinan, tandatanda persalinan, dan tanda bahaya persalinan didapatkan bahwa sebagian besar ibu nifas sudah mengetahui pengertian persalinan itu adalah proses pengeluaran hasil konsepsi (janin dan plasenta) yang telah cukup bulan atau dapat hidup diluar kandungan melalui jalan lahir atau melalui jalan lain dengan bantuan atau tanpa bantuan (kekuatan sendiri). Tandatanda persalinan antara lain adalah sakit pinggang menjalar ke ari-ari, keluar air-air, lendir bercampur darah, ibu merasa ingi meneran bersamaan dengan terjadinya kontraksi, ibu merasakan adanya peningkatan pada anus atau vaginanya, perinium menonjol. Adapun tanda bahaya persalinan adalah bayi tidak lahir dalam 12 jam sejak terasa mules, tali pusat atau tangan bayi keluar dari jalan lahir, ibu tidak kuat mengejan atau mengalami kejang, air ketuban keruh dan berbau, setelah bayi lahir, ari-ari tidak keluar, ibu gelisah atau mengalami kesakitan yang hebat, sesak atau asma serta perdarahan.
Hasil wawancara mendalam terhadap 5 orang informan utama, mengenai pengetahuan ibu tentang pengertian persalinan, tanda-tanda persalinan dan tanda bahaya persalinan sudah baik, semua ibu sudah mengetahui apa itu pengertian persalinan, tanda-tanda persalinan dan tanda bahaya persalinan tetapi belum memahami lebih mendalam lagi.

Penelitian ini sesuai dengan penelitian Buyandaya yang menemukan bahwa responden yang berpengetahuan cukup, memilih tenaga kesehatan sebagai penolong persalinannya dan responden yang berpengetahuan kurang, memilih tenaga non kesehatan sebagai penolong. ${ }^{5}$ Penelitian lain yang mendukung adalah Penelitian Asriani yang menunjukkan adanya hubungan antara pengetahuan dengan pemilihan tenaga penolong persalinan. Semakin tinggi tingkat pengetahuan ibu, semakin tinggi singkat pemamfaatan penolong persalinan. ${ }^{6}$

\section{c. Sikap}

Dari hasil wawancara mendalam terhadap 5 orang informan utama tentang bagaimana sikap ibu nifas dalam memilih tenaga penolong persalinan didapatkan, bahwa ada 3 orang yang memilih bersalin ke dukun bayi dan 2 orang ke bidan.

Hasil wawancara mendalam dan observasi pada informan tentang sikap ibu dalam memilih tenaga penolong persalinan dapat dilihat dengan jawaban yang diberikan tentang pertanyaan dengan siapa ibu memilih bersalin, bagi ibu yang bersalin dipetugas kesehatan (bidan) tetap memilih bidan, dengan alasan bahwa anak pertama sudah sama bidan, dan kalau ada apaapa bidan bisa langsung merujuk ke rumah sakit. Lain halnya dengan ibu yang bersalin di dukun bayi, perasaan aman dan percaya sudah turun temurun. 
Penelitian ini didukung oleh teori yang dikemukakan oleh Yeyeh bahwa sikap merupakan reaksi tertutup seseorang dan dapat dipengaruhi oleh pengetahuan, keyakinan, pikiran dan emosi sehingga sikap dapat berubah menjadi positif dan negatif. ${ }^{7}$ Sikap ibu dalam memilih petugas kesehatan (bidan), adalah bahwa bidan sudah menempuh pendidikan, sehingga pengetahuan dalam menolong persalinan sudah dipahami oleh bidan dan jika terjadi suatu komplikasi maka dapat ditangani dengan cepat. Lain halnya sikap ibu yang bersalin didukun bayi, perasaan aman mereka dapatkan dimana perawatan dari mulai persalinan sampai selesai dilakukan oleh dukun bayi yang didalamnya juga terdapat tradisi dan budaya yang dijalankan, faktor pengalaman dukun yang lebih dan keramahan dukun bayi serta sentuhan-sentuhan yang diberikan. Penelitian ini sesuai dengan penelitian Sodikin yang menunjukkan bahwa ada hubungan antara sikap terhadap pelayanan kesehatan dengan pemanfaatan pertolongan persalinan oleh tenaga kesehatan. Apabila individu memiliki sikap yang mendukung terhadap pelayanan kesehatan maka cendrung akan mencari dan memanfaatkan pelayanan kesehatan. ${ }^{8}$ Penelitian ini juga sesuai dengan Pangemanan yang menunjukkan bahwa ada hubungan antara sikap terhadap pelayanan kesehatan dengan pemanfaatan penolong persalinan oleh tenaga kesehatan. ${ }^{9}$

Pada penelitian ini peneliti mendapatkan, bahwa sikap informan utama terhadap pemilihan tenaga penolong persalinan berdasarkan pengalaman dari anak pertama. Jika informan merasa nyaman terhadap penolong persalinan tersebut (dukun bayi/bidan) maka selanjutnya akan tetap bersalin ke tenaga penolong tersebut.

\section{d. Sosial Budaya}

Dari hasil wawancara mendalam terhadap 5 orang informan utama tentang sosial budaya bersalin ke dukun bayi memang sudah turun temurun. Masyarakat Tembilahan hulu yang berada di wilayah kerja puskesmas tembilahan hulu, pada umumnya masih memegang teguh tradisi dan budaya saat ibu mulai hamil, persalinan, sampai selesai masa nifas. Agama yang dianut oleh masyarakat setempat, yakni 99,9\% agama islam dan suku yang berada di wilayah kerja Puskesmas Tembilahan hulu ini berbeda-beda, sehingga tradisipun tergantung suku masing-masing.

Penelitian ini didukung oleh teori yang dikemukakan oleh Saifuddin ${ }^{1}$ bahwa salah satu kebudayaan Indonesia yang masih ada adalah persalinan dan kelahiran dengan bantuan dukun bayi, terutama pada masyarakat pedesaan. Hal ini sulit dihilangkan karena merupakan tradisi yang sudah berjalan lama dan turun temurun. Sementara bidan desa meski sudah profesional belum mampu menciptakan pamor seperti dukun bayi. Didesa masih banyak yang beranggapan bahwa apabila orang tuanya dulu bersalin di rumah maka anak-anaknya diharapkan melahirkan keturunan di rumah juga.

Penelitian ini juga didukung oleh penelitian Syarief dan Nilakesuma yang mengatakan bahwa sosial budaya memiliki ikatan yang kuat terhadap seseorang dalam mengambil keputusan, terutama pemilihan tenaga penolong persalinan oleh ibu. Budaya yang kental dengan adat istiadat daerah dapat merubah suatu keputusan, sehingga budaya sangat mempengaruhi tingkat pemilihan penolong persalinan. ${ }^{10}$

\section{e. Akses Ke Pelayanan Kesehatan}

Berdasarkan hasil observasi yang dilakukan oleh peneliti, terhadap kondisi geografis khususnya akses menuju ke pelayanan kesehatan sangat tidak memungkinkan, apalagi yang di Desa Sungai Intan, dengan kondisi alam pasang surut yang penghubungnya adalah parit dan sungai menyebabkan transportasi yang sulit. Jarak pelayanan kesehatan yang tidakterjangkau oleh 
masyarakat dapat mengakibatkan masyarakat memilih untuk mencari pertolongan persalinan yang lebih dekat. Jawaban dari informan utama maupun informan pendukung yang mengatakan bahwa yang menyebabkan persalinan dengan dukun bayi di wilayah kerja puskesmas Tembilahan Hulu, dikarenakan jarak dan waktu tempuh yang jauh dari fasilitas kesehatn. Seperti di Desa Sungai Intan berjarak 2 kilo dengan berjalan kaki, kemudian naik pompong melewati parit-parit, selanjutnya sungai, itupun kalau air pasang, kalau air surut pompong tidak bisa lewat. Karena lokasi rumah penduduk yang terpencil, jauh dari fasilitas kesehatan, sehingga masyarakat lebih memilih bersalin dirumah. Selain minimnya sarana transportasi, persepsi yang salah tentang keamanan persalinan di rumah juga menyebabkan masyarakat memilih untuk melahirkan di rumah.

Penelitian ini didukung oleh teori yang dikemukakan Model McGarthy dalam Saifuddin bahwa akses terhadap pelayanan kesehatan dipengaruhi oleh lokasi dan kondisi geografis, jenis pelayanan yang tersedia, kualitas pelayanan, transportasi, dan akses terhadap informasi. ${ }^{1}$

Penelitian ini juga didukung oleh penelitian Jahidin dkk di polewali Mandar bahwa aksebilitas ketempat pelayanan kesehatan merupakan penghambat untuk memamfaatkan pelayanan kesehatan tertentu seperti sarana transportasi, keadaan geografis dan waktu tempuh untuk menuju tempat pelayanan kesehatan. ${ }^{11}$

Pada penelitian ini peneliti mendapatkan, bahwa akses ke pelayanan kesehatan sangat sulit, dari 5 desa yang ada di wilayah kerja tembilahan hulu, Desa Sungai Intan yang aksesnya sangat sulit. Untuk menuju ke fasilitas kesehatan membutuhkan waktu yang sangat lama serta transportasi yang sulit, mulai dari jalan kaki, naik pompong (nunggu air pasang), sampai akhirnya harus naik mobil/ojek. Oleh karena itu bagi masyyarakat yang tinggal di Desa Sungai Intan akan memilih bersalin ke dukun bayi.

\section{f. Dukungan Keluarga}

Dari hasil wawancara mendalam kepada lima orang informan utama tentang bagaimana dukungan suami/keluarga dalam kehamilan dan persalinan ibu. 3 ibu nifas mendapatkan dukungan dari suaminya, sementara 2 ibu nifas lainnya tidak mendapatkan dukungan dari suaminya. Berdasarkan hasil wawancara dan observasi dengan informan utama tentang dukungan suami/keluarga di wilayah kerja puskesmas Tembilahan Hulu, bahwa suami/keluarga sangat berperan, suami dan keluarga yang memilihkan penolong persalinan.

Penelitian ini juga didukung oleh penelitian Sufiawati yang menunjukkan bahwa perilaku pemilihan penolong persalinan oleh ibu sangat tergantung pada suami/dukungan keluarganya, bisa dilihat pada keluarga yang suaminya/ keluarganya tidak mendukung untuk ditolong oleh tenaga kesehatan, maka ibu tersebut akan mempertimbangkan pilihannya untuk bersalin ke tenaga kesehatan atau pada dukun bayi. Sebaliknya bila suami/keluarganya mendukung persalinannya ditolong oleh tenaga kesehatan maka ibu tersebut termotivasi untuk memilih tenaga kesehatan sebagai penolong persalinan. ${ }^{12}$ Karena dukungan suami/keluarga sangat kuat dalam memberikan motivasi pada perilaku ibu dalam memilih tenaga penolong persalinannya, maka tenaga kesehatan harus melakukan upayaupaya pendekatan pada suami/keluarga sejak masa kehamilan melalui penyuluhan persalinan yang bersih dan aman.

\section{KESIMPULAN DAN SARAN}

Berdasarkan hasil wawancara dan pembahasan, dapat disimpulkan bahwa tentang perilaku ibu dalam memilih tenaga penolong persalinan di wilayak Puskesmas Tembilahan Hulu, maka dapat disimpulkan sebagai berikut :

1. Perilaku ibu dalam memilih tenaga penolong persalinan masih banyak ke dukun bayi dibandingkan ke tenaga kesehatan/bidan. 
2. Pengetahuan informan tentang persalinan di wilayah kerja Puskesmas tembilahan Hulu sudah baik, walaupun ibu belum mengetahui secara mendalam.

3. Sikap informan, kebanyakan masih bersikap acuh tak acuh terhadap pelayanan kesehatan, ini dapat dilihat pada hasil penelitian pemilihan tenaga penolong persalinan masih ada beberapa yang memilih bersalin ke dukun bayi.

4. Pemilihan tenaga penolong persalinan masih kental dengan tradisi turun temurun bersalin ke dukun bayi.

5. Akses ke pelayanan kesehatan masih sangat susah, dapat dilihat di satu desa yaitu Desa Sungai Intan, dimana masyarakat jika ingin ke pelayanan kesehatan harus menempuh jarak yang jauh, selain itu harus menggunakan transportasi yang berbeda, dan mengikuti kondisi alam pasang surut.

6. Masih ada beberapa yang tidak mendukung istrinya untuk bersalin ke tenaga kesehatan.

Berdasarkan dari hasil penelitian yang telah dilakukan, peneliti merekomendasikan beberapa saran kepada:

\section{Kepala Puskesmas Tembilahan Hulu}

a. Melakukan evaluasi/penilaian kerja terhadap pemegang program PWS KIA dan Bidan yang berada di wilayah kerja Puskesmas Tembilahan Hulu agar dapat optimal dalam pemilihan tenaga penolong persalinan.

b. Kualitas pelayanan pertolongan persalinan ditingkatkan melalui peningkatan kompetensi bidan puskesmas melalui pelatihan.

c. Sebaiknya sebelum bidan ditugaskan perlu pembekalan pengetahuan budaya kepada bidan melalui orientasi puskesmas sebelum melaksanakan tugas di masyarakat. d. Di setiap desa ada Rumah Tunggu Kelahiran (RTK), agar setiap ibu-ibu yang ingin bersalin tidak perlu jauh-jauh ke fasilitas kesehatan lagi.

e. Di desa yang jauh dari jangkaun puskesmas atau pustu agar dapat menempatkan bidan desa sesuai dengan jangkaun masyarakat.

\section{Bagi Pemegang Program PWS-KIA}

a. Menggalakkan program P4K (Program Perencanaan Persalinan dan Pencegahan Komplikasi) di wilayah kerja puskesmas Tembilahan Hulu.

b. Merevitalisasi kembali kemitraan bidan dan dukun bayi diwilayah kerja Puskesmas Tembilahan Hulu dalam rangka meningkatkan cakupan persalinan oleh tenaga kesehatan.

c. Memberikan pelatihan kepada kader guna meningkatkan kualitas dan kemampuan kader dalam pendataan ibu hamil guna meningkatkan cakupan persalinan ke tenaga kesehatan.

\section{Bagi Bidan}

a. Memperhatikan penyuluhan tentang persalinan, tanda-tanda persalinan, bahaya persalinan, pemilihan tenaga penolong persalinan sehingga penyuluhan dan pengawasan dilapangan dapat berjalan lebih optimal sehingga meningkatkan pengetahuan keluarga maupun ibu yang akan bersalin.

b. Mampu menjalin hubungan yang baik dengan masyarakat (terutama ibu hamil).

c. Memberikan penyuluhan-penyuluhan kepada masyarakat tentang Persalinan dan pemilihan tenaga penolong per-salinan yaitu ke tenaga kesehatan (bidan). 


\section{DAFTAR PUSTAKA}

1. Saifuddin (Eds). Ilmu Kebidanan, Jakarta: Yayasan Bina Pustaka Sarwono Prawirohardjo, 2009.

2. Eka Puspita, Anik Maryunani. Program Perencanaan Persalinan dan Pencegahan Komplikasi (P4K). Jakarta : CV. Trans Info Media, 2013.

3. Manuaba. Ilmu Kebidanan Penyakit Kandungan dan Keluarga Berencana Untuk Pendidikan Bidan, Jakarta : EGC,2010.

4. Survey Demografi Kesehatan Indonesia (SDKI). Angka Kematian Ibu Melahirkan. (http:/share. pdfoline.com), 2012.

5. Buyandaya. Tahir Abdullah, Syamsir S. russeng Faktor Determinan Pemilihan Tenaga Penolong Persalinan di Wilayah Kerja Puskesmas Palasa Kabupaten Parigi Moutong. Jurnal. Sulawesi Tengah ,2012.

6. Asriani. Faktor-Faktor yang Berhubungan dengan Pemilihan Penolong Persalinan oleh Ibu Bersalin di Wilayah Kerja Puskesmas Barombong Kelurahan Barombong. Jurnal Kesehatan Volume II No. 4 Tahun 2009.

7. Sujiyatini Ai Yeyeh, Dewi Purwaningsih. Asuhan Kebidanan 2 (Persalinan). Jakarta : Trans Info Media, 2009.
8. Sodikin, Ova Emilia, Koentjoro. Determinan Perilaku Suami yang Mempengaruhi Pilihan Penolong Persalinan Bagi Istri. Berita Kedokteran Masyarakat Vol. 25, No. 1, Maret, 2009.

9. Pangemenan, Relik Diana Parenden, Kandau. Analisis Keputusan Ibu Memilih Penolong Persalinan di Wilayah Puskesmas Kabila Bone. Jurnal, 2015.

10. Syarief dan Nilakesuma. Faktor Predisposi Dalam Pemilihan Tenaga Penolong Persalinan di Kabupaten Solok Selatan. Skripsi : Mercubaktijaya Padang, 2013.

11. Jahidin, Koentjoro. Nilakusuma . Faktor Determinan yang Mempengaruhi Alternative Pemilihan Persalinan Dukun Beranak di Kacamatan Limboro Kabupaten polewali Mandar. Stikes Bina Generasi Polewali Mandar. Fakultas Kesehatan Masyaarakat: Universitas Hasanuddin Makassar. Vol. 14, No. 2, juni 2012.

12. Sufiawati, W. Faktor-Faktor yang Berhubungan dengan Pemilihan Tenaga Penolong Persalinan di Puskesmas Cibadak Kabupaten Lebak Provinsi Banten. Jakarta. Skripsi : Universitas Indonesia, 2012. 